\title{
Transformações no Envolvimento Paterno ao Longo dos Seis Primeiros Meses do Bebê na Creche ${ }^{1}$
}

\author{
Marília Reginato Gabriel ${ }^{2}$ \\ Rita de Cássia Sobreira Lopes \\ Universidade Federal do Rio Grande do Sul
}

\begin{abstract}
RESUMO - Este trabalho investigou o envolvimento de pais com seus bebês e com a creche nos seis primeiros meses de frequência do bebê no berçário. Por meio de um estudo de caso coletivo de caráter longitudinal, quatro pais responderam a entrevistas em três momentos: entrada do bebê na creche, um mês e 6 meses depois da entrada. Análise de conteúdo qualitativa indicou que tanto a creche como o desenvolvimento do bebê foram aliados do pai para a retomada do trabalho e da vida conjugal. O estudo mostra a importância de se levar em consideração as necessidades e competências do pai que está envolvido no cuidado ao bebê.
\end{abstract}

Palavras-chave: envolvimento paterno, relações pai-criança, papel dos pais, pai, creche

\section{Changes in Father Involvement During the First Six Months of the Baby in the Child Care}

\begin{abstract}
This study investigated father involvement with their babies and the child care center during the first six months after the baby entered in the day care center. It was performed a collective case study, with a longitudinal design, in which four fathers answered an interview at three moments: entry in the child care center, one month and six months later. Qualitative content analysis indicated that the day care center and the baby's development helped the father to be more involved with his work and his personal life. The present study shows the importance of taking into consideration the needs and capacity of fathers involved in infant care.
\end{abstract}

Keywords: father involvement, father child relations, parental role, fathers, child day care

A passagem para um novo estágio de vida pode ter implicações intensas para o indivíduo, assim como para o funcionamento do sistema familiar (Carter \& McGoldrick, 1995; Hintz, 2001; Minuchin, 1982). Em particular, a inauguração do subsistema parental, representado pela gravidez, nascimento e primeiros meses do bebê, é caracterizada como um dos maiores desafios vividos pela família (Bradt, 1995), implicando em uma mudança importante nos papéis familiares.

O papel de pai tem sido considerado como um dos mais afetados pelas transformações vividas pelo homem na contemporaneidade (Parke, 1997). A participação da mulher no mercado de trabalho tem sido sugerida frequentemente como uma das principais fontes de mudanças nos papéis parentais e no modo como a família se organiza. Entre outras modificações, a maior participação paterna e a necessidade de terceiros no cuidado e na educação dos seus filhos tornaram-se as mais evidentes (Hintz, 2001; Seabra, 2007; Vitória \& Rossetti-Ferreira, 1993). Outras mudanças ambientais ocorridas nas últimas décadas, como a invenção

1 Esse artigo é derivado da Dissertação de Mestrado defendida pela primeira autora, sob a orientação da segunda autora, junto ao Programa de Pós-graduação em Psicologia da Universidade Federal do Rio Grande do Sul, Porto Alegre, RS (Gabriel, 2012).

2 Endereço para correspondência: Universidade Federal do Rio Grande do Sul, Campus Universitário, Instituto de Psicologia, Rua Ramiro Barcelos, 2600 sala 108/111, Bairro Santa Cecília, Porto Alegre, RS, Brasil. CEP: 90035-003.E-mail: gabrielmarilia@yahoo.com.br de um arsenal de instrumentos, instituições e saberes para a criação dos filhos, transformaram o modo como pais e mães vivem a rotina com seu bebê (Dessen, 2010). Desde produtos de higiene e alimentação específicos para bebês, até mesmo a criação de um sistema educacional de cuidados alternativos aos familiares, foram constituídos para dar conta da complexidade e das exigências de ter um bebê na atualidade (Lamb, Pleck, Charnov, \& Levine, 1985).

Os cuidados alternativos têm um importante papel na vida de pais e mães, uma vez que, além da rotina de trabalho ser intensa para ambos, dificilmente poderão contar com a família de origem para ajudar nos cuidados do bebê, opção mais utilizada quando a prioridade é deixar o bebê em casa (Seabra, 2007), seguida da babá/empregada (Rapoport \& Piccinini, 2004), considerando o contexto brasileiro. Essa impossibilidade acontece pelo motivo de os avós estarem distantes geograficamente ou também pelo fato de que aquele modelo antigo de avós e tias disponíveis pela aposentadoria já não é realidade para a maioria das famílias (Lamb, 1999; Rapoport \& Piccinini, 2004).

Entretanto, os cuidados alternativos aos da mãe, do pai, da babá ou da família extensa são necessários principalmente quando a mãe volta ao trabalho após um período de recuperação do parto e do período inicial de amamentação (Rapoport \& Piccinini, 2004), ou quando a proteção legal da licença maternidade termina (Lordelo, 1997). Frente a essas questões, a opção de cuidado mais frequente no mundo 
ocidental passa a ser a creche (Lordelo, 1997; Rapoport \& Piccinini, 2001).

O pai, como figura frequentemente percebida como distante e pouco participativa do cuidado com o bebê (Vieira et al., 2014), torna-se importante e essencial nesse cenário, uma vez que a mãe também está envolvida com suas questões profissionais e a creche precisa da colaboração da família para ser um ambiente adequado para o bebê. O envolvimento paterno tende a variar de acordo com as situações que são impostas à família (Parke, 1997) e o fato de o bebê frequentar a creche pode ser um fator que também afeta o envolvimento do pai, uma vez que se caracteriza por um ambiente a mais responsável pelo cuidado do bebê, com características e exigências próprias.

Embora seja possível encontrar algumas publicações sobre a paternidade de bebês que frequentam creche (p. ex., Atkinson, 1987, 1991; Ceglowski, Shears, \& Furman, 2010; Crepaldi, Andreani, Hammes, Ristof, \& Abreu, 2006; Fagan, 1994, 1997; Frieman \& Berkeley, 2002; Seabra, 2007), a grande parte dos estudos possui como foco o envolvimento do pai com a creche do bebê e não há investigações de como se dá o envolvimento do pai com o bebê que frequenta a instituição. Nesse sentido, o presente estudo teve por objetivo investigar as transformações no envolvimento paterno com o bebê que frequenta a creche, assim como no envolvimento com a creche do bebê ao longo dos seis primeiros meses do bebê na creche.

A escolha por essa perspectiva teórica se deu em função da escassez de um conceito consolidado no estudo da paternidade em diversos estudos nacionais e internacionais localizados sobre o tema. O estudo da paternidade através de um conceito integrado tem sido enfatizado a fim de se entenderem as dinâmicas dessa vivência de maneira padronizada (Cabrera, Tamis-LeMonda, Lamb, \& Boller, 1999). Investir no estudo da paternidade através do modelo de envolvimento paterno proposto por Lamb et al. (1985), atentando para as peculiaridades do conceito, tem sido uma sugestão de pesquisadores da área e está sendo levado em consideração para a presente pesquisa. Cabe, então, apresentar brevemente os seus principais componentes.

O modelo de envolvimento paterno estrutura-se através de três componentes: (a) interação, (b) disponibilidade e (c) responsabilidade. A categoria Interação refere-se ao contato direto do pai com seu filho, por meio do cuidado e atividades compartilhadas. Diz respeito aos cuidados, brincadeiras, passeios, estímulos, entre outras interações diretas do pai com seu filho. Foram incluídas nessa categoria as interações do pai com a creche que o bebê frequenta. A categoria Disponibilidade é um aspecto relacionado à acessibilidade física e psicológica, o que oportuniza a interação com a criança. Esse componente permite, mas não requer, uma interação face-a-face. A acessibilidade do pai para a interação com a creche foi incluída nessa categoria. A categoria Responsabilidade se refere ao papel do pai de garantir que a criança seja cuidada e que os recursos estejam disponíveis para a criança. Responsabilidade também inclui ansiedade, preocupações e planejamentos que fazem parte da parentalidade, incluindo, assim, a responsabilidade pelos cuidados alternativos adotados para o filho (Lamb et al., 1985). Nesse sentido, o presente estudo investigou as transformações no envolvimento paterno, a partir de seus três componentes ao longo dos seis primeiros meses do bebê na creche.

\section{Método}

\section{Participantes}

Participaram do estudo quatro pais de bebês que ingressaram no berçário de uma creche universitária pública no ano de 2011, entre 32 e 36 anos de idade no início da coleta de dados, residentes em Porto Alegre, RS. Eles foram selecionados a partir da amostra do estudo Impacto da Creche no Desenvolvimento Socioemocional e Cognitivo infantil: Estudo Longitudinal do Primeiro ao Segundo Ano de Vida da Criança (CRESCI; Piccinini, Becker, Martins, Lopes, \& Sperb, 2010), que recebeu aprovação do Comitê de Ética e Pesquisa do Instituto de Psicologia da Universidade Federal do Rio Grande do Sul (UFRGS; Processo no 2010070, de 06/12/2010).

Entre os 54 pais acompanhados nesse projeto, os quatro pais foram selecionados para este estudo com base nos seguintes critérios: (a) idade inicial superior a 25 anos e inferior a 40 anos, (b) realização de todas as etapas de coleta de dados ao longo de 2011 e (c) manutenção da relação de casal, com coabitação, no mínimo, desde a gestação. Para o bebê, os critérios foram: (a) ter ingressado em uma creche

Tabela 1. Dados demográficos da família

\begin{tabular}{|c|c|c|c|c|c|c|c|c|c|c|c|}
\hline Caso & Bebê & $\begin{array}{c}\text { Idade do } \\
\text { bebê na } \\
\text { Fase } 1\end{array}$ & Pai & $\begin{array}{c}\text { Idade } \\
\text { do } \\
\text { pai }\end{array}$ & $\begin{array}{l}\text { Escolaridade } \\
\text { do pai }\end{array}$ & Profissão & Mãe & $\begin{array}{c}\text { Idade } \\
\text { da } \\
\text { mãe }\end{array}$ & $\begin{array}{l}\text { Escolaridade } \\
\text { da mãe }\end{array}$ & $\begin{array}{c}\text { Tempo } \\
\text { que o } \\
\text { casal está } \\
\text { junto }\end{array}$ & $\begin{array}{l}\text { Renda } \\
\text { Familiar }\end{array}$ \\
\hline 01 & Carolina (Carol) & 7 meses & Mateus & 32 & $\begin{array}{l}\text { Ensino } \\
\text { Superior } \\
\text { Completo }\end{array}$ & Auditor & Gisele & 32 & $\begin{array}{l}\text { Ensino Superior } \\
\text { Completo }\end{array}$ & 5 anos & 7500,00 \\
\hline 02 & Gustavo & 6 meses & Solano & 36 & $\begin{array}{l}\text { Ensino } \\
\text { Superior } \\
\text { Incompleto }\end{array}$ & Livreiro & Fernanda & 37 & $\begin{array}{l}\text { Ensino Superior } \\
\text { Completo }\end{array}$ & 10 anos & 6000,00 \\
\hline 03 & João Paulo & 5 meses & Hermes & 36 & $\begin{array}{l}\text { Ensino } \\
\text { Superior } \\
\text { Completo }\end{array}$ & Contador & Denise & 36 & $\begin{array}{l}\text { Ensino Superior } \\
\text { Incompleto }\end{array}$ & 4 anos & 9000,00 \\
\hline 04 & Luiz Otávio & 6 meses & Germano & 34 & Pós-Graduação & Professor & Letícia & 32 & Pós-Graduação & 6 anos & 5500,00 \\
\hline
\end{tabular}


pública ligada à universidade em março de 2011, (b) no momento do ingresso, estar em torno dos seis meses de vida e (c) não ter problemas de saúde graves (ver Tabela 1). Todas as mães eram funcionárias públicas da universidade e eram participantes do CRESCI (Piccinini et al., 2010).

\section{Delineamento, Procedimentos e Instrumentos}

Foi utilizado um delineamento de estudo de caso coletivo (Stake, 1994), de caráter longitudinal, buscando investigar as transformações no envolvimento de pais de bebês que estão na creche. Cada caso foi investigado em três momentos: antes da entrada na creche, um mês e seis meses após a entrada na creche.

Conforme procedimento estipulado no projeto CRESCI (Piccinini et al., 2010), os pais foram contatados inicialmente na creche, durante entrevistas de rotina realizadas pelos profissionais na instituição. Nessa ocasião, foi realizada uma breve apresentação da pesquisa aos pais e os mesmos foram informados que, no momento em que o bebê ingressasse na creche, a pesquisadora retomaria o contato. No caso dos pais que não estiveram presentes nesse primeiro momento, o convite foi feito por meio da mãe do bebê. Quando o contato foi retomado, os pais foram convidados a participar da pesquisa e, após o aceite, assinaram o Termo de Consentimento Livre e Esclarecido. Os pais que concordaram em participar do estudo foram vistos individualmente, na UFRGS ou na creche, em horário agendado previamente.

$\mathrm{Na}$ entrada do bebê na creche, o pai foi solicitado a preencher a Ficha de Dados Demográficos da Família (Núcleo de Infância e Família [NUDIF - UFRGS], 2011d) e a responder à Entrevista sobre a Gestação, Parto e a Experiência de Paternidade (NUDIF - UFRGS, 2011a). Essa fase foi realizada até um dia antes da entrada do bebê na creche, uma vez que se objetivava investigar como o envolvimento paterno acontece antes do ingresso do bebê na instituição, permitindo comparar as transformações do envolvimento paterno antes e depois da creche.

Ao final do primeiro mês de cada bebê na creche, o pai respondeu à Entrevista sobre a Adaptação do Bebê à Creche - Versão do Pai (NUDIF - UFRGS, 2011b), uma vez que o foco dessa fase foi o processo de adaptação do bebê à creche. Aos 6 meses após a primeira coleta, os pais responderam à Entrevista sobre o Envolvimento Paterno na Rotina do Bebê (NUDIF - UFRGS, 2011c), com a finalidade de acompanhar as transformações do envolvimento paterno no decorrer dos meses. Todas as entrevistas foram gravadas e transcritas literalmente para análise.

\section{Resultados}

A análise de conteúdo qualitativa (Bardin, 1977; Laville \& Dionne, 1999) das entrevistas foi utilizada para investigar, em cada caso, o envolvimento paterno na entrada do bebê na creche (por volta dos 6 meses de idade do bebê), na adaptação do bebê à creche e após 6 meses da entrada do bebê na creche (cerca dos 12 meses de idade do bebê). Assim, as categorias estabelecidas - Interação, Disponibilidade e Responsabilidade - basearam-se nas dimensões de envolvimento paterno de Lamb et al. (1985).

A partir da identificação desses temas nas entrevistas, elaborou-se um relato longitudinal de cada caso. Com base nesse procedimento, apresenta-se uma breve descrição de cada caso ao longo dos três momentos investigados ${ }^{1}$. Após a exposição dos quatro casos, são discutidas as semelhanças entre eles no que se refere às transformações na interação, disponibilidade e responsabilidade do pai com o bebê que frequenta a creche e com a instituição.

\section{Caso 1 - De Mãe a Pai: O Caso de Mateus, Gisele e Carolina $^{2}$}

Interação. Antes da entrada de Carolina na creche, Mateus realizava todas as tarefas de cuidado da filha ao longo do dia, além dos momentos de brincadeiras, que objetivavam estimular e distrair o bebê. O pai sentia-se "como uma mãe" ao dedicar-se inteiramente para o bebê e ao atender às necessidades da filha. Com a entrada de Carolina na creche, Mateus passou a fazer viagens a trabalho. Nas suas ausências, a avó materna assumia os cuidados da neta. Com relação à creche, o pai participou da adaptação da filha, permanecendo na instituição enquanto a filha passava as suas primeiras horas com as educadoras. No entanto, a interação com a creche foi assumida pela esposa, pois o pai sentia-se insatisfeito com a relação que as educadoras estabeleciam com os genitores. O pai acreditava que as educadoras não passavam informações precisas sobre a rotina da filha. Seis meses após a entrada de Carolina na creche, o pai, quando estava em casa, continuava assumindo os cuidados da filha - alimentação, banho, trocas de roupa e fralda. No entanto, com a maior frequência das viagens do pai, esses momentos se restringiram aos finais de semana e alguns dias da semana. As interações por meio de brincadeiras também se mantiveram, principalmente com fins de estimulação. Com relação à creche, o pai costumava buscar o bebê no fim do turno da manhã, por volta das 14 horas. Após os 6 meses frequentando a creche, o pai passou a interagir com as educadoras, conversando sobre o que a filha fez durante o período em que permanecia na instituição: "Todo o dia eu ia lá falava com a mocinha da portaria, entrava, sabia o nome de todos os amigos da Carol, conhecia todos".

Disponibilidade. Na primeira fase, o pai possuía um emprego cuja carga horária ocupava 5 dias do mês. Nos outros dias, o pai permanecia em casa cuidando da filha e da rotina da família. O pai também costumava trabalhar em casa, em projetos pessoais, estando disponível para a filha, mesmo que não estivesse em interação direta. No entanto, por ser um bebê, Carolina demandava interação constante, $\mathrm{o}$ que impedia ao pai dedicar-se o quanto e como gostaria para o trabalho e para si mesmo. O pai acreditava que a grande disponibilidade que possuía também estava fazendo com que a esposa se afastasse dele, pois não estava de acordo com o que se esperaria tradicionalmente de um pai ou marido.

1 Na dissertação da qual provém este artigo (Gabriel, 2012), há inúmeras vinhetas que exemplificam cada categoria. Por motivo de espaço, somente algumas serão apresentadas.

2 Todos os nomes utilizados são fictícios. 
Com a entrada do bebê na creche, o pai pôde destinar o período que o bebê estava na creche para dedicar-se ao trabalho e, quando a filha voltava da creche, o pai assumia novamente os cuidados. O pai mostrou-se saudoso por ficar longe do bebê e lamentou precisar abrir mão do convívio com a filha para assumir um lugar tradicional de marido e pai. Seis meses após a entrada na creche, ao realizar viagens constantes, a disponibilidade de Mateus para a filha alterou-se em grande parte, em comparação com a primeira fase. Os finais de semana passaram a ser os principais dias em que o pai estava disponível para a filha. O pai entendia que, com essa mudança, conseguiu oferecer mais qualidade na interação com a filha, dedicando-se com exclusividade, ao contrário das fases anteriores em que havia quantidade de tempo, mas o pai dividia-se entre o cuidado da filha e o trabalho. Com isso, o pai percebeu que a creche também se dedicava exclusivamente para o cuidado e estimulação dos bebês, valorizando esse espaço.

Responsabilidade. Na primeira fase, o pai preocupavase em garantir um desenvolvimento saudável da filha tanto em nível físico como cognitivo e emocional, levando-a a especialistas quando possuía alguma preocupação maior. Na rotina diária, o pai preocupava-se em oferecer estímulos para que a filha se desenvolvesse por meio de brincadeiras, passeios e através de uma relação saudável com o pai e a mãe. Nesse sentido, o pai preocupava-se com a entrada da filha na creche, pensando em um possível sofrimento da filha por estar afastada de casa, embora reconhecesse que, na creche, a filha entraria em contato com outras pessoas, $\mathrm{o}$ que beneficiaria seu desenvolvimento. Por contribuir com grande parte da renda familiar, o pai se preocupava com os aspectos financeiros da família, fato que também o fez buscar outras fontes de renda. No período de adaptação à creche, o pai preocupava-se com o desenvolvimento emocional do bebê, principalmente com a reação da filha ao novo contexto. O pai passou a se preocupar com a educação da filha, pois agora estava sob cuidados de outras pessoas que não seus genitores (avó materna e creche). Em relação à creche, a maior preocupação do pai era quanto à alimentação da filha, pois temia que o modo como a creche oferecia os alimentos pudesse causar uma regressão no desenvolvimento da filha. $\mathrm{Na}$ terceira fase, percebeu-se que a principal preocupação de Mateus era quanto ao desenvolvimento emocional da filha, principalmente no que se refere aos possíveis efeitos de sua relação conjugal e do ambiente familiar que oferecia à filha. $\mathrm{O}$ pai acreditava que a filha percebia quando o casal estava bem e quando estava em conflito, sendo que essa ambiguidade poderia ter um impacto no desenvolvimento emocional da filha. Outra preocupação do pai era quanto ao modo como a mãe vinha tratando a filha, referindo-se às reprimendas da mãe, as quais o pai acreditava serem exageradas e incongruentes com os comportamentos da filha. Além disso, mesmo com a mãe contribuindo para o orçamento da família, o pai acreditava que seria a partir de seu esforço que possibilitaria o aumento da renda familiar. Dessa forma, o pai estava preocupado em trabalhar para oferecer para a filha uma educação de qualidade: "O trabalho gera frutos e daqui a pouco, eu posso ter a segurança de colocar ela [bebê] em uma escola boa. Isso custa dinheiro! Fica totalmente para mim".

\section{Caso 2 - Sou Cogenitor: O Caso de Solano, Fernanda e Gustavo}

Interação. Na primeira fase, Solano realizava todas as atividades voltadas ao bebê de modo compartilhado com a mãe. O pai percebia que não participava com maior frequência dos cuidados do bebê, pois precisava trabalhar durante o dia e pelo fato de o bebê ser amamentado, necessitando da mãe em diversos momentos do dia: "se ele está com fome, tem que ser com ela [mãe]. Não tem muito assim o que eu fazer, além de trocar, dar o banho". O pai também interagia com o filho por meio de brincadeiras que estimulassem o bebê, demonstrando intenso prazer com o filho. Sobre a creche, o pai participou de reuniões e de visitas para conhecer a creche, sentindo-se seguro com a instituição. Após um mês na creche, Solano passou a cuidar do bebê sozinho, quando a mãe possuía algum compromisso, além de realizar tarefas como preparar o material a ser levado à instituição. Depois que o bebê passou a frequentar a creche, Solano passou a brincar mais com o filho, permitindo-se pegar mais o bebê no colo, fato compreendido pelo pai como uma compensação pelo dia que o bebê passou longe do pai e da mãe. Com relação à creche, o pai costumava levar o bebê para a instituição, buscar eventualmente e conversar com as educadoras sobre como o bebê passou o dia ou a noite. Seis meses após a entrada na creche, além dos cuidados e brincadeiras já realizados nas fases anteriores, Solano levava o bebê para a creche de manhã e eventualmente o buscava. Nesses momentos, o pai procurava saber sobre o dia do bebê, principalmente sobre a alimentação. A combinação entre o pai e a mãe era de que quem se liberasse antes das atividades laborais buscaria o bebê na creche. A intenção era permanecer o maior tempo possível com o bebê em casa.

Disponibilidade. Antes da entrada do bebê na creche, enquanto o bebê e a mãe estavam em casa, a rotina do pai estava organizada de modo a permanecer o maior tempo possível com a família. O pai ficava em casa no início da manhã, ao meio-dia, à noite e aos finais de semana. Eventualmente, Solano precisava viajar a trabalho e não conseguia retornar para o almoço, inclusive passava alguns dias em outras cidades. O pai considerava difícil cuidar do bebê sem a ajuda de alguém, solicitando que a avó materna o substituísse em algumas tarefas. Um mês após a entrada, com a mudança na rotina, o pai e a mãe passaram a não se encontrar no intervalo do almoço, enquanto o bebê permanecia na creche. Com a entrada do bebê na creche, Solano entendeu que o pai ou a mãe precisava estar disponível para caso a creche solicitasse que o bebê fosse atendido por um dos responsáveis. Como os horários de trabalho da mãe eram mais rígidos, Solano ficava atento para possíveis contatos e, ainda, buscava outras fontes de apoio quando sabia que não estaria disponível, como o apoio do irmão. Com relação à disponibilidade para interação em casa, o pai observou que depois que o bebê foi para a creche, os momentos em que o infante brincava sozinho eram mais frequentes e se estendiam por mais tempo. O brincar sozinho 
possibilitava ao pai que permanecesse disponível por alguns momentos e não em interação direta todo o tempo. Após seis meses do bebê na creche, percebeu-se que a disponibilidade do pai se manteve desde a fase de adaptação, organizando a sua rotina pelas necessidades do filho e da creche.

Responsabilidade. Na primeira fase, Solano expressava um sentimento de maior responsabilidade com o nascimento do filho, ao entender que o desenvolvimento, bem-estar e educação do filho dependiam do cuidado dos genitores. Antes de o filho entrar na creche, o pai preocupava-se com a separação entre bebê e genitores, considerando-a precoce, embora inevitável devido à necessidade de ambos os genitores voltarem ao trabalho. Mesmo assim, o pai acreditava que a creche iria trazer benefícios para o desenvolvimento do filho e que ele seria bem cuidado na instituição. Na adaptação do bebê à creche, o pai estava atento com o que o bebê comia na instituição, a qual deveria seguir as recomendações médicas de inclusão de novos alimentos, excluindo guloseimas ou alimentos não saudáveis: "Eu me senti seguro em relação a eles [creche], são bem organizados, efetivos. Nesse negócio de comida, que é uma coisa bem nossa, não pode, porcaria, bala, chiclé, pirulitos". Houve um episódio em que a creche não seguiu a recomendação (incluiu feijão na dieta) e Solano preocupou-se em conversar com as educadoras e com a nutricionista, a fim de entender a situação e esclarecer que o bebê ainda não poderia comer tal alimento. Na terceira fase, o pai preocupava-se no sentido de garantir que o bebê estivesse bem atendido na creche, seguindo o que os genitores acreditavam que fosse saudável para o seu desenvolvimento. Assim, o pai procurava buscar e levar informações para outros setores da creche, além das educadoras. Ao mesmo tempo, o pai ressaltou os benefícios da creche e a segurança que possuía na instituição.

\section{Caso 3 - Sou Pai: O Caso de Hermes, Denise e João Paulo}

Interação. Antes da entrada do bebê na creche, a interação de Hermes se restringia à noite, quando o pai compartilhava alguns cuidados com a mãe, como ficar com o bebê enquanto esta preparava o jantar, e a mãe cuidava do bebê enquanto o pai lavava a louça. O pai costumava interagir com o bebê por meio de passeios e viagens com a família. A interação do pai com a creche, antes da entrada do bebê, foi por meio de uma reunião para pais e mães e através de conversas com a esposa, a qual mantinha maior proximidade com a instituição. Um mês após a entrada na creche, a interação do pai com o bebê se alterou com a mudança de horários do seu trabalho. O pai interagia com o filho de manhã, antes de o filho ir para a creche e após as 21 horas, quando retornava para casa. Com a manhã livre e com o filho na creche, o pai passou a estudar nesse turno. Desse modo, o pai pôde dedicar-se exclusivamente para o filho aos finais de semana ou quando o bebê estava em casa, compartilhando os cuidados com a mãe e brincando com o bebê. Quanto à interação com a creche, o pai não costumava ter um contato direto com a instituição, com a exceção de ter participado de uma reunião de pais e mães. O pai afirmou que tentava participar indiretamente por meio da organização do material do filho ("mochilinha") utilizado na creche. Seis meses após a entrada, a interação com o filho se manteve como na fase anterior, em que a interação pai-bebê estava restrita à noite $\mathrm{e}$ aos finais de semana, quando o pai participava das tarefas de cuidado do bebê, como dar banho e alimentar. O pai sentia que os finais de semana eram de intensa interação com o bebê, pois este manifestava maior disposição para brincar e buscava ficar perto dos genitores, compensando a distância da semana. Nos finais de semana, o pai procurava estudar em um dos dias livres. No entanto, considerava difícil manter essa programação por conta das atividades com o bebê, como passear, brincar, dançar, alimentar, dar banho. Em relação à creche, o contato do pai com a instituição acontecia por meio das conversas com as professoras, quando o pai levava o bebê à creche, duas vezes por semana, ou em eventos, como o dia dos pais e aniversário do bebê. O pai acrescentou que o fato de bebê estar na creche oportunizou ao casal momentos para conversar, cuidar da casa juntos ou estudarem para seus projetos pessoais.

Disponibilidade. Antes da entrada na creche, a disponibilidade do pai durante o dia era determinada pela carga horária e pela flexibilidade do seu emprego. O pai saía de casa às 9 horas e retornava às 18 horas, sendo que não possuía autorização para sair durante o expediente. Os horários livres do pai eram destinados para o estudo para concursos. No entanto, mesmo que essa fosse a programação do pai, este acreditava que o filho acabava tomando o seu tempo livre, com os cuidados e as brincadeiras: "Eu invisto o meu tempo em ficar mais com o João Paulo e estudar, quando eu não tô trabalhando. Hoje muito menos estudar, mais o João Paulo". Um mês após a entrada na creche, o pai passou a trabalhar das $14 \mathrm{~h}$ às $21 \mathrm{~h}$ e a estudar em casa pelas manhãs. Com a nova rotina de trabalho e estudos, o pai sentia que não estava conseguindo participar da vida do filho o quanto gostaria e que a falta de disponibilidade de tempo estava afastando-o do filho durante a semana. A fim de compensar o tempo que não podiam passar juntos e o sentimento de distanciamento, o pai estava abrindo mão de seus estudos durante os finais de semana. Já seis meses após a entrada na creche, a disponibilidade do pai mantevese desde que João Paulo entrou na creche. O pai trabalhava nos turnos da tarde e da noite, priorizando os estudos pela manhã, enquanto o bebê estava na creche e a mãe estava no trabalho. Os finais de semana eram divididos entre a atenção ao filho e ao estudo. Quanto à disponibilidade para a creche, Hermes não se dispunha para interagir com a instituição, permanecendo com Denise essa responsabilidade.

Responsabilidade. Um mês antes da entrada do bebê na creche, o pai mostrava responsabilizar-se pelo sustento do bebê e em oferecer para o filho mais do que teve na sua infância. Além disso, Hermes preocupava-se em oferecer para João Paulo uma família em que as pessoas tivessem boas relações, principalmente entre o pai e a mãe, além de fazer o filho sentir-se amado. Quanto à creche, o pai preocupavase em assegurar-se que a instituição iria tratar seu filho com carinho e atenção. Um mês após a entrada do bebê na creche, o pai ainda se preocupava com a sobrecarga de tarefas que a mãe assumia, pois a esposa não estava conseguindo realizar todas as tarefas domésticas e também cuidar do bebê e estudar. Para que a esposa não se sobrecarregasse, o pai 
estava pensando em contratar alguém para ajudar no cuidado com a casa. Quanto à creche, o pai estava preocupado com a troca da equipe que trabalhava na instituição, mobilizando-se junto com outros pais e mães a manifestarem sua insatisfação com a mudança: "O João Paulo adora ir pra creche [...] isso é uma coisa que deixa a gente confortável, porque deixar teu filho com pessoas estranhas nunca é uma tarefa muito simples. Quando começa a ter essa confiança, se mudam as pessoas, ela se abala também". No momento de adaptação do bebê à creche, o pai também se preocupava com a separação precoce do filho e da mãe. O pai lamentou não ter condições financeiras para manter a esposa em casa cuidando do bebê, mesmo que este não fosse o desejo de Denise. Assim como na primeira fase, seis meses após a entrada, o pai responsabilizava-se em garantir para o filho uma relação tranquila entre pai e mãe e um ambiente em que estivesse seguro e que proporcionasse segurança. Quanto à creche, nos primeiros seis meses, a mãe foi a responsável pela rotina do bebê com a creche. Embora o pai tivesse levado o bebê para a instituição algumas vezes, não assumia a tarefa como de sua responsabilidade, sendo que geralmente acompanhava a mãe quando esta levava o bebê à creche.

\section{Caso 4 - Quero ser Mãe: O Caso de Germano, Letícia e Luiz Otávio}

Interação. Na entrada do bebê na creche, o pai interagia por meio de cuidados básicos e brincadeiras. Como o bebê precisava da mãe por conta da amamentação, Germano procurava auxiliar nas tarefas domésticas, para as quais tinha dificuldades de se organizar. O pai alternava com a mãe os cuidados da casa e o cuidado do bebê: enquanto um realizava as tarefas domésticas, outro cuidava do filho. Percebeu-se que o pai interagia com o filho como uma resposta à esposa, que, segundo o pai, centralizava-se no bebê e tomava frente nos cuidados: "Logo no início eu fazia questão de fazer algumas coisas. Então, por exemplo, trocar a fralda, no início ela [mãe] trocava, e eu dizia: 'Não, não, eu troco!' E eu peguei o jeito assim". O pai relatou que, quando a mãe o deixava sozinho com o bebê, ele aproveitava esse momento para cuidá-lo à sua maneira e aproximar-se dele. Na fase de adaptação, um mês após a entrada, o pai realizava atividades como transportar mãe e bebê, fazer compras, cuidar da casa e cuidar do bebê apenas quando a mãe precisava fazer algo sozinha. Dessa forma, o pai sentia que a sua participação nos cuidados do filho era limitada pela esposa. Germano entendia que a esposa tomava frente nos cuidados e que ele precisava ser mais ágil ou pedir para executar as tarefas para poder realizá-las. Para o pai, a entrada do bebê na creche trouxe a necessidade de sua participação, principalmente para buscar o filho. Antes da entrada, o pai relatou que o seu envolvimento fora dispensado pela mãe. A respeito da creche, a relação que o pai estabeleceu com a mãe repetiuse. Germano sentia que a instituição não valorizava a figura paterna. O pai revelou que procurou desfazer essa imagem de pai por meio do seu envolvimento com a instituição. Seis meses após a entrada, o pai buscava o filho na creche, trocava fralda e alimentava o bebê nos finais de tarde até a chegada da mãe. Além do cuidado diário, principalmente aos finais de tarde e finais de semana, estavam o brincar, passear, dançar e, também, interações que buscassem acalmar o filho, quando este estava irritado. Ademais, o pai relatou cuidados eventuais, como levar ao médico e fazer vacinas, os quais o pai procurava realizar sem a mãe, pois, dessa forma, sentia-se à vontade para tirar as suas dúvidas em relação à saúde do bebê. A respeito da creche, o pai costumava conversar com as educadoras sobre o que aconteceu durante o dia do bebê, a fim de dar continuidade à rotina do filho. Mesmo com eventuais desagrados, o pai relatou uma relação diferente com a creche. O pai revelou que, com o passar do tempo, espelhou-se na relação de outros pais e mães com as educadoras, o que o fez agir de modo diferente, agradecendo os cuidados para as educadoras e sentindo-se mais respeitado também.

Disponibilidade. Antes da entrada na creche, o pai trabalhava 40 horas semanais, com dois turnos livres para poder preparar aula e corrigir provas dos alunos. O pai procurava utilizar seus turnos livres para trabalhar, mas, quando estava cuidando do bebê, sentia dificuldade para conciliar as duas tarefas, priorizando a sua atenção para o bebê. Assim, na maioria das vezes, o pai estava utilizando esses momentos para cuidar do filho ou fazer atividades com a esposa. Com o bebê na creche, o pai disponibilizou-se a buscar o filho na maioria dos dias e a permanecer com ele em caso de doença. Como o bebê estava frequentando a creche e a esposa estava de volta à rotina de trabalho, o pai relatou poder utilizar seus períodos de folga para as suas próprias atividades: "Durante a creche, eu fico com um espaço pra fazer coisas de escola [corrigir provas], agora me facilitou também pra eu ter esse espaço". Seis meses após a entrada, a disponibilidade do pai se manteve, com dois turnos livres durante a semana e no final da tarde, quando buscava o bebê na creche e o levava ao médico, quando necessário. Em casa, o pai observou que o bebê, então com 12 meses, não necessitava de interação sempre que estava com o pai. Após um período inicial de interação, o bebê conseguia permanecer com o pai, estando este apenas disponível para quando o bebê precisasse. $\mathrm{O}$ pai relatou que, com a entrada do bebê na creche, estava disponível para eventuais solicitações da instituição e para buscar o bebê. Além disso, enquanto o bebê estava na creche, o pai pôde utilizar os seus turnos livres para realizar atividades do trabalho.

Responsabilidade. Antes da entrada, o pai preocupavase em estabelecer com o filho uma relação paterna diferente da que tivera com seu próprio pai, no sentido de ser uma figura representativa para o filho. O pai se preocupava também em não reproduzir alguns aspectos da relação com a própria mãe, principalmente o modo de proteger o filho, visto como demasiado por Germano. Com relação à creche, o pai questionava sua qualidade por ser uma instituição pública, geralmente entendida como de baixa qualidade e desatenta as necessidades das crianças. Com a entrada do bebê na creche, o pai passou a preocupar-se com os aspectos educacionais do filho. O pai buscou garantir que a creche atenderia o seu filho com qualidade: preocupações básicas, como alimentação, até a imposição de limites para o filho foram questões citadas pelo pai. Seis meses após a entrada, o pai se preocupava com a educação do bebê, em transmitir valores para o filho desde a infância e de não estimular o bebê a brincadeiras que pudessem acarretar problemas no 
futuro, segundo o pai, como brincar com a direção do carro. Em relação à creche, o pai reconhecia que a creche também assumia esse tipo cuidado. Pela sua disponibilidade durante a semana, o pai assumiu responsabilidades como levar ao médico e fazer vacinas. O pai sentia grande prazer em ser responsável pelo bebê tanto nos cuidados da saúde como ser a primeira referência da creche quando esta necessitava entrar em contato com os genitores: "Eles [creche] ligaram pra mim me perguntando se ele [bebê] podia comer carne. Eles ligam primeiro pra mim, entendeu?".

\section{Discussão}

A partir da análise dos resultados, pode-se destacar dois principais aspectos relacionados às transformações no envolvimento do pai: (a) o desenvolvimento do bebê e (b) a entrada na creche. Dessa forma, para fins de discussão, as categorias de análise de dados serão subdivididas em desenvolvimento e creche.

\section{Interação}

Aspectos relacionados ao desenvolvimento do bebê. Com relação à interação por meio de brincadeiras e passeios, as falas dos pais sugerem que, ao brincar, os laços pai-bebê eram aproximados. O período do desenvolvimento emocional do bebê permitia que o pai e o bebê se engajassem em interações que eram próprias da dupla. Embora as atividades do pai não possam mais ser compreendidas como compostas exclusivamente de brincadeiras, o papel de socializador ainda é importante para o bebê (Silva \& Piccinini, 2007). Inclusive, assim como o pai tem compartilhado as tarefas de cuidado com o bebê, as mães têm se envolvido com atividades lúdicas na mesma proporção que os pais (Monteiro, Veríssimo, Santos, \& Vaughn., 2008).

O desenvolvimento físico e cognitivo do bebê é um fator importante para a relação pai-bebê, sendo que a qualidade desta se torna cada vez melhor com o desenvolvimento e a capacidade de se comunicar do filho (Silva \& Piccinini, 2007). A participação paterna é essencial para a qualidade da relação, pois, quanto maior a participação, melhor a comunicação entre pai e filho, no sentido de haver sincronia na interação, marcada por um tom emocional positivo (Monteiro et al., 2008). Além do mais, os pais sentem satisfação com o contato físico e pela capacidade paterna deste de reconfortar o bebê (Monteiro et al., 2008).

Aspectos relacionados à entrada na creche. Com a entrada na creche, o relacionamento entre pai e filho se tornou mais intenso aos finais de tarde e finais de semana, pois os pais entendiam que o bebê exigia mais atenção nesses momentos e tentavam recompensar o período em que estiveram afastados (casos Mateus, Solano e Hermes).

Com relação à interação com a creche, esta se mostra um indicador importante do envolvimento paterno com as atividades do bebê. Em todos os casos, a mãe era a pessoa que possuía a ligação formal com a creche por ser funcionária da instituição. Os pais interagiam com a creche principalmente ao levar e/ou ao buscar a criança e ao conversar com as educadoras. Outras formas de interação eram as conversas com outros profissionais da creche, como enfermeira, equipe diretiva, psicóloga e nutricionista, e também se envolver em reuniões de pais.

As atividades relacionadas à creche do filho de que o pai participava estão de acordo com outros estudos nos quais o pai participava de diversas atividades tais como as mencionadas acima (Atkinson, 1987; Seabra, 2007). No estudo de Atkinson (1987), que contou com 24 pais e 39 mães, $83 \%$ dos pais declararam participar conversando com as cuidadoras e $71 \%$ buscando e levando o bebê na instituição. No presente estudo, os pais tendiam a participar de uma forma geral, tanto em atividades rotineiras como em momentos especiais como festividades e reuniões, ao contrário do estudo de Seabra (2007), em que o pai participava significativamente mais das festividades do que das atividades cotidianas. Inclusive, o pai Germano lamentou não poder participar da festa de aniversário do filho, ainda que buscasse o bebê todos os dias na creche. Com relação às atividades cotidianas, a comunicação com as educadoras é a atividade mais frequente do pai (Atkinson, 1987; Fagan, 1997), sendo a alimentação do bebê o assunto mais abordado (Fagan, 1997), assim como na presente pesquisa, em que, em dois casos, a alimentação foi tema até mesmo de conflitos entre pai e escola.

Percebe-se que os pais participantes da presente pesquisa interagiam com a creche de forma frequente seja diretamente, ao entrar em contato com a creche, como indiretamente, ao organizar o material a ser levado para a creche ou conversando com a mãe sobre as atividades do bebê na instituição. Os pais podem oferecer suporte indireto essencial para a mãe realizar os cuidados diretos com qualidade para o bebê, como preparar o bebê para ser levado à escola, embora esse tipo de atividade não seja reconhecido pelas mães (Atkinson, 1987).

\section{Disponibilidade}

Aspectos relacionados ao desenvolvimento do bebê. Observou-se que a disponibilidade dos pais alterou-se com o desenvolvimento do bebê e de sua capacidade de permanecer sozinho por alguns momentos. Com isso, os pais puderam estar apenas disponíveis para o infante e não em interação por todo o tempo. Os pais alegaram que a criança conseguia ficar mais tempo brincando sozinha e, assim, os pais podiam ficar ao lado do bebê fazendo outras atividades. $\mathrm{O}$ pai do caso 2 relata que esses momentos em que o bebê estava brincando sozinho favorecia o contato íntimo do casal, principalmente por meio de conversas. Já no caso 3 , o pai relatou que, com o bebê na creche, o casal permanecia sozinho em casa, possibilitando conversas e atividades exclusivamente conjugais.

Aspectos relacionados à entrada na creche. Com a entrada do bebê na creche, o pai passou a utilizar o tempo em que a criança estava sendo cuidada pela creche para dedicarse mais ao trabalho (casos Mateus, Solano e Germano) e a projetos pessoais (casos Hermes e Germano). Mesmo utilizando o tempo em que o bebê estava na creche para dedicar-se a si mesmo, quando o pai estava com o bebê nos finais de tarde ou finais de semana, conseguia dedicar-se exclusivamente à criança, diferente do que acontecia antes do bebê ir à creche.

Quanto à disponibilidade em relação à creche, observouse que os pais mostravam-se dispostos e acessíveis para interagir com as educadoras e outros profissionais. Os pais, ao buscar e levar o bebê, mostravam-se disponíveis para 
eventuais contatos. Segundo Fagan (1997), o fato de os pais destinarem cerca de 15 minutos tanto para buscar como para levar o bebê demonstraria essa acessibilidade à instituição.

Mesmo que o fato de exercer uma atividade laboral não seja uma explicação suficiente para o grau de envolvimento paterno, uma vez que ambos os genitores trabalham e o bebê está na creche (Monteiro et al., 2008), fica evidente que o tipo de trabalho exercido afeta a disponibilidade tanto do pai como da mãe. Com exceção do pai Hermes, nos outros casos, o genitor que assumia o levar ou buscar o bebê na creche ou ainda o estar disponível ao longo do dia é o que possuía um trabalho que não exigia horários fixos (casos Mateus e Solano), ou em que há possibilidade de negociação com o chefe (caso Germano). Atkinson (1987) sugere que os pais possam combinar trabalho e papéis familiares por meio de uma flexibilidade maior em suas agendas de trabalho.

\section{Responsabilidade}

Aspectos relacionados ao desenvolvimento do bebê. Percebeu-se que os pais passaram a compartilhar mais os cuidados com a mãe depois que o bebê entrou na creche. Isso pode estar atrelado ao fato de ser inserida a alimentação sólida, além das mamadas. Inclusive, o crescimento do bebê facilitou o manejo para o pai, o que pode também estar influenciando esse assumir responsabilidades, bem como a diminuição do contato com a mãe, que voltou a trabalhar e abriu espaço para a participação paterna (Seabra \& Seidl-deMoura, 2011). Atualmente, além das tarefas de cuidado serem compartilhadas com a mãe, acrescenta-se a responsabilidade de garantir que o filho tenha um desenvolvimento emocional saudável, sendo que os pais estão conscientes da sua contribuição para tanto, como visto nos casos. Com isso, percebe-se uma mudança qualitativa na relação pai-filho, pois esta não está baseada somente na provisão material e no pai como sinônimo de lei (Fulgencio, 2007), mas sim associada a atividades ditas maternas, como se preocupar com os aspectos educacionais e emocionais (Freitas, Silva, Coelho, Guedes, \& Costa, 2009).

Aspectos relacionados à entrada na creche. Percebeuse que, com a entrada na creche, os pais passaram a compartilhar de maneira mais frequente os cuidados do bebê e a responsabilizar-se por atividades relacionadas à creche. Com o pai Germano, especialmente, percebeu-se que, antes da entrada na creche e no período de adaptação, havia uma intensa necessidade de o pai de sentir-se responsável por algumas atividades do bebê, a fim de ter mais contato com ele e de não permitir que a esposa centralizasse todas as tarefas voltadas ao bebê. Isso se refletiu na relação do pai com a creche, sendo que o pai não se sentia reconhecido pelas educadoras como alguém interessado em informar-se sobre o bebê. Seis meses após a entrada na creche, o pai relatou outra perspectiva em relação aos cuidados do bebê, assumindo responsabilidades importantes, como estar em licença para cuidar do filho doente e ainda perceber que, na creche, tem sido valorizado. Atkinson (1987) enfatiza que os profissionais devem reconhecer o pai como parte do sistema de cuidado da criança, provendo-o das informações necessárias sobre seu filho. Para tanto, as educadoras devem conhecer os aspectos que englobam a paternidade e entender a perspectiva paterna de cuidado (Frieman \& Berkeley, 2002).
Quanto à creche, os pais Mateus, Solano e Germano responsabilizavam-se por buscar e levar o bebê à instituição. Antes da entrada, os pais participaram de reuniões para conhecer a creche, sendo que se colocam ativos no processo de escolha (Atkinson, 1987, 1991; Ceglowski et al., 2010; Seabra, 2007), mesmo sendo uma creche pública, destinada aos servidores. Inicialmente preocupados, reação comum de pais ao colocarem seus filhos sob cuidado de terceiros (Rapoport \& Piccinini, 2004; Vitória \& Rossetti-Ferreira, 1993), os pais sentiram-se confiantes para deixar a criança sob cuidado das educadoras.

Os pais se preocupam com a qualidade do serviço oferecido pela escola para o seu bebê, sendo que, quanto mais envolvidos os pais estão, maior probabilidade de reconhecer as habilidades e conhecimentos necessários pra a qualidade da creche (Atkinson, 1991). Segundo Atkinson (1987), os aspectos que mais preocupam os pais são (a) a sensibilidade para o atendimento das necessidades do filho (70\%), (b) a segurança física da criança (37\%) e (c) as oportunidades de aprendizagem a fim de tornarem-se autossuficientes (33\%). Para avaliar a creche, o pai tenta perceber se o filho está feliz e se gosta de ir para a creche (Atkinson, 1987), assim como a segurança e a abertura e frequência das comunicações com as cuidadoras (Ceglowski et al., 2010).

De modo geral, os pais relataram que estavam satisfeitos com a qualidade da creche, os cuidados com o bebê e com o fato de a creche ter proporcionado que o pai voltasse a se dedicar para si mesmo e para a esposa. Pode-se relacionar essa última informação com o estudo realizado com mães sobre a participação dos pais nos cuidados dos filhos (Crepaldi et al., 2006). Esse estudo revela que os pais de bebês que frequentam creche são menos participativos do que pais de bebês que não utilizam esse cuidado alternativo. Pode-se relacionar a menor participação paterna ao fato de a família contar com um terceiro para responsabilizar-se pelos cuidados do bebê e, ainda, ao oportunizar que o pai possa dedicar a sua atenção a si mesmo e para as suas atividades laborais, antes destinada ao bebê, como visto no presente estudo.

Assim como no presente estudo, principalmente nos casos 1, 2 e 4, não há diferenças significativas em termos quantitativos entre o pai e a mãe com relação a quem assume a responsabilidade de buscar ou levar o filho na creche (Fagan, 1997). Já o resultado de Seabra (2007), em que as mães são prioritariamente as responsáveis, é compatível com o caso 3. Um fator importante que pode também explicar esses diferentes resultados é a distância entre a creche e o local do trabalho, ou o horário de início e fim do turno de trabalho. Esses aspectos são determinantes para a escolha de qual dos cônjuges buscará e levará o filho à creche, sendo que quem trabalha mais perto ou chega a tempo de buscar ou levar o bebê, assume as tarefas, independente de ser o pai ou a mãe (Fagan, 1994, 1997). Outro fator é o nível de exigência do trabalho, sendo que pais com empregos que exigem uma maior dedicação não conseguem se dedicar às atividades escolares do filho (Fagan, 1994). 


\section{Considerações Finais}

Como discutido anteriormente, observou-se que a creche e o desenvolvimento do bebê são aliados do pai no retorno às suas atividades, principalmente ao trabalho. A creche possibilita que o pai dedique o tempo em que o bebê está na instituição para realizar atividades pessoais, para ficar mais tempo no trabalho e, até mesmo, conseguir ficar somente com a esposa por algumas horas. Este mostrou ser um dos principais resultados deste estudo, sendo que a creche contribuiu para que o pai pudesse voltar-se as suas tarefas pessoais, especialmente ao trabalho. Em tempos de um envolvimento considerável do pai com o bebê, a creche pode ser entendida como um terceiro membro na relação pai-bebê, que libera o pai para a realidade do mundo externo (trabalho, relação conjugal). Para o pai, e atualmente também para a mãe, o trabalho possui papel central em sua identidade: é através da atividade laboral que o pai encontra meios de prover a família e de sentir-se útil a ela (Gomes \& Resende, 2004).

A respeito do envolvimento paterno com a creche, ao contar com um cuidado alternativo, exige-se do pai que este se envolva com as atividades relacionadas à instituição, tais como se comunicar com as educadoras, buscar e levar o filho, arrumá-lo para a ir à creche. A creche, diferente de outros cuidados alternativos, possui uma rotina que precisa ser seguida pelos pais e mães, a qual, de certa forma, exige que os genitores se envolvam com ela, como ter horários fixos para deixar e buscar o bebê, reuniões de pais, estar disponível para algum imprevisto. Entende-se que o envolvimento do pai em atividades indiretas, mas que dizem respeito ao filho, é um importante indicativo de como o pai se envolve com o próprio bebê (Atkinson, 1987). Além do mais, essas atividades indiretas são essenciais para a execução das tarefas diretas, muitas vezes desempenhadas pela mãe (Atkinson, 1991).

Por fim, este estudo pôde contribuir para a compreensão do envolvimento de uma das figuras mais importantes para o desenvolvimento infantil - o pai. Investigar o envolvimento do pai com o seu bebê que frequenta a creche e com a própria creche torna-se essencial para a promoção de um melhor cuidado para as crianças (Ceglowski et al., 2010). Para tanto, é necessário entender o ponto de vista e as necessidades de todas as pessoas que são responsáveis pelo cuidado do bebê (Atkinson, 1987).

\section{Referências}

Atkinson, A. M. (1987). Fathers' participation and evaluation of a family day care. Family Relations, 36(1), 146-151.

Atkinson, A. M. (1991). Father's participation in day care. Early Child Development and Care, 66(1), 115-126.

Bardin, L. (1977). Análise de conteúdo. Lisboa: Edições70.

Bradt, J. O. (1995). Tornando-se pais: Famílias com filhos pequenos. In B. Carter \& M. McGoldrick (Eds.), As mudanças no ciclo de vida familiar: Uma estrutura para a terapia familiar (pp. 206-222). Porto Alegre: Artmed.
Cabrera, N. J., Tamis-LeMonda, C. S., Lamb, M. E., \& Boller, K. (1999, August). Measuring father involvement in the early Head Start evaluation: A multidimensional conceptualization. Paper presented at the National Conference on Health Statistics, Washington, D. C.

Carter, B., \& McGoldrick, M. (1995). As mudanças no ciclo de vida familiar: uma estrutura para a terapia familiar. In B. Carter \& M. McGoldrick (Eds.), As mudanças no ciclo de vida familiar: Uma estrutura para a terapia familiar (pp. 7-27). Porto Alegre: ArtMed.

Ceglowski, D., Shears, J., \& Furman, R. (2010). "I want child care he's gonna be happy in": A case study of a father's child care experience. Early Education and Development, 21(1), 1-20.

Crepaldi, M. A., Andreani, G., Hammes, P. S., Ristof, C. D., \& Abreu, S. R. (2006). A participação do pai nos cuidados da criança, segundo a concepção de mães. Psicologia em Estudo, $11(3), 579-587$.

Dessen, M. A. (2010). Estudando a família em desenvolvimento: Desafios conceituais e teóricos. Psicologia: Ciência e Profissão, 30(número especial), 201-219.

Fagan, J. (1994). Mother and father involvement in day care centers serving infants and young toddlers. Early Child Development and Care, 103(1), 95-101.

Fagan, J. (1997). Patterns of mother and father involvement in day care. Child \& Youth Care Forum, 26(2), 113-126.

Freitas, W. M. F., Silva, A. T. M. C., Coelho, E. A. C., Guedes, R. N., \& Costa, A. M. T. (2009). Paternidade: responsabilidade social do homem no papel de provedor. Revista de Saúde Pública, 43(1), 85-90.

Frieman, B. B., \& Berkeley, T. R. (2002). Encouraging fathers to participated in the school experiences of young children: The teacher's role. Early Childhood Education Journal, 29(3), 209-213.

Fulgencio, C. D. R. (2007). A presença do pai no processo de amadurecimento: Um estudo sobre D. W. Winnicott (Unpublished master's thesis). Pontifícia Universidade Católica de São Paulo, São Paulo, Brasil.

Hintz, H. C. (2001). Novos tempos, novas famílias? Da modernidade à pós-modernidade. Pensando Famílias, 3, 8-19.

Gabriel, M. R. (2012). Transformações no envolvimento paterno ao longo dos seis primeiros meses do bebê na creche (Unpublished doctoral dissertation). Universidade Federal do Rio Grande do Sul, Porto Alegre, Brasil.

Gomes, A. J. S., \& Resende, V. R. (2004). O pai presente: O desvelar da paternidade em uma família contemporânea. Psicologia: Teoria e Pesquisa, 20(2), 119-125.

Lamb, M. E. (1999). Parental behavior, family processes, and child development in nontradicional and traditionally understudied families. In Parenting and child development in "nontraditional” families (pp. 1-14). New Jersey: Lawrence Erlbaum Associates.

Lamb, M. E., Pleck, J. H., Charnov, E. L., \& Levine, J. A. (1985). Paternal behavior in humans. American Zoologist, 25(3), 883-894.

Laville, C., \& Dione, J. (1999). A construção do saber: Manual de metodologia da pesquisa em ciências humanas. Porto Alegre: Artes Médicas.

Lordelo, E. R. (1997). Efeitos da experiência de creche no desenvolvimento da criança: Uma revisão. Psicologia: Teoria e Pesquisa, 13(2), 221-229. 
Minuchin, S. (1982). Famílias: Funcionamento e Tratamento . Porto Alegre: Artes Médicas.

Monteiro, L., Veríssimo, M., Santos, A. J., \& Vaughn, B. E. (2008). Envolvimento paterno e organização dos comportamentos de base segura das crianças em famílias portuguesas. Análise Psicológica, 3(26), 395-409.

Núcleo de Infância e Família - Universidade Federal do Rio Grande do Sul. (2011a). Entrevista sobre a adaptação do bebè à creche-versão pai (Instrumento não publicado). Universidade Federal do Rio Grande do Sul, Porto Alegre, Brasil.

Núcleo de Infância e Família - Universidade Federal do Rio Grande do Sul (2011b). Entrevista sobre a gestação, parto e a experiência da paternidade (Instrumento não publicado). Universidade Federal do Rio Grande do Sul, Porto Alegre, Brasil.

Núcleo de Infância e Família - Universidade Federal do Rio Grande do Sul (2011c). Entrevista sobre o envolvimento paterno na rotina do bebê (Instrumento não publicado). Universidade Federal do Rio Grande do Sul, Porto Alegre, Brasil.

Núcleo de Infância e Família - Universidade Federal do Rio Grande do Sul (2011d). Ficha de dados demográficos da família (Instrumento não publicado). Universidade Federal do Rio Grande do Sul, Porto Alegre, Brasil.

Parke, R. D. (1997). Fatherhood. Cambrigde: Harvard University Press.

Piccinini, C. A., Becker, S. M. S., Martins, G. D .F., Lopes, R., \& Sperb, T. (2012). O impacto da creche no desenvolvimento socioemocional e cognitivo infantil: estudo longitudinal do sexto mês de vida do bebê ao final dos anos pré-escolares (Projeto de Pesquisa não publicado). Universidade Federal do Rio Grande do Sul, Porto Alegre, Brasil.
Rapoport, A., \& Piccinini, C. A. (2001). O ingresso e adaptação de bebês e crianças pequenas à creche: alguns aspectos críticos. Psicologia: Reflexão e Crítica, 14(1), 81-95.

Rapoport, A., \& Piccinini, C. A. (2004). A escolha do cuidado alternativo para o bebê e a criança pequena. Estudos de Psicologia, 9(3), 497-503.

Seabra, K. C. (2007). A paternidade em famílias urbanas: Análise da participação do pai na creche-escola e nos cuidados com os filhos (Unpublished doctoral dissertation). Universidade do Estado do Rio de Janeiro, Rio de Janeiro, Brasil.

Seabra, K. C., \& Seidl-de-Moura, M. L. (2011). Cuidados paternos nos primeiros três anos de vida dos filhos: Um estudo longitudinal. Interação em Psicologia, 15, 135-147.

Silva, M. R., \& Piccinini, C. A. (2007). Sentimentos sobre paternidade e o envolvimento paterno: um estudo qualitativo. Estudos de Psicologia, 24(4), 561-573.

Solis-Ponton, L. (2004). A construção da parentalidade. São Paulo: Casa do Psicólogo.

Stake, R. E. (1994). Case Studies. In N. K. Denzin \& Y. S. Lincoln (Eds.), Handbook of Qualitative Research (pp. 236-247). Thousand Oaks: Sage Publications.

Vieira, M. L., Bossardi, C. N., Gomes, L. B., Bolze, S. D. A., Crepaldi, M. A., \& Piccinini, C. A. (2014). Paternidade no Brasil: Revisão sistemática de artigos empíricos. Arquivos Brasileiros de Psicologia, 66, 36-52.

Vitória, T., \& Rossetti-Ferreira, M. C. (1993). Processos de adaptação na creche. Cadernos de Pesquisa, 86, 55-64

Recebido em 09.12.2012

Primeira decisão editorial em 08.05.2015

Versão final em 12.02.2016

Aceito em 23.03.2016 